\title{
Peningkatan Pelayanan Penyediaan Air Minum Kota Blitar
}

\author{
Ichwan Rahmawan Widodo dan Hari Wiko Indarjanto \\ Departemen Teknik Lingkungan, Fakultas Teknik Sipil dan Perencanaan, Institut Teknologi Sepuluh \\ Nopember (ITS) \\ e-mail: ichwan.rahmawan@gmail.com; hwi_corp@yahoo.com
}

\begin{abstract}
Abstrak - Perusahaan Daerah Air Minum (PDAM) Kota Blitar melayani sekitar 38.160 jiwa dari total jumlah penduduk Kota Blitar 145.111 jiwa. Cakupan pelayanan PDAM sebesar 26\% (2016), Dalam penelitian ini dilakukan analisis pada jaringan primer dan sekunder eksisting untuk mendapatkan kondisi sistem sebagai dasar peningkatan pelayanan. Peningkatan pelayanan dilakukan dengan analisis real demand survei yang bertujuan untuk mengetahui faktor yang mempengaruhi masyarakat agar berlangganan kembali. Analisis sistem menggunakan EPANET, yang mensimulasi jaringan sehingga didapatkan output berupa headloss, kecepatan aliran, dan sisa tekan. Empat puluh satu pipa memiliki kecepatan aliran kurang dari $0,3 \mathrm{~m} / \mathrm{s}$ berpotensi terjadi endapan suspended solid (Fe dan Mn) yang menyebabkan penyempitan pipa. Penyempitan ini akan meningkatkan headloss sistem sehingga dapat menurunkan tekanan air (terjadi pada blok 1, 2, 19, 20, 23 dan 24) yang menyebabkan air tidak dapat mengalir ke pelanggan. Pemasangan pipa paralel pada pipa yang memiliki headloss lebih dari $20 \mathrm{~m}$ ternyata dapat menurunkan headloss dan meningkatkan tekanan air. Peningkatan pelayanan, sumur bor masih dapat menampung debit peningkatan tahap 1 sebesar 1301/s dan tahap 2 sebesar 1501/s. Sistem perpipaan masih mampu digunakan untuk pengembangan tersebut. Pelanggan mengharapkan pihak PDAM Kota Blitar agar melakukan perbaikan terutama terkait dengan tingkat kejernihan air, bau dan rasa air. PDAM perlu mengolah air sumur bor karena $\mathrm{Fe}$ dan Mn yang tinggi.
\end{abstract}

Kata Kunci-Sistem Distribusi, Air Minum, PDAM, Kota Blitar, EPANET.

\section{PENDAHULUAN}

C AKUPAN pelayanan air bersih nasional saat ini baru mencapai $74 \%$ berdasarkan sasaran Rencana Pembangunan Jangka Menengah Nasional (RPJMN) 20152019. Komitmen Pemerintah yang tercantum pada Kebijakan Strategi Nasional Sistem Penyediaan Air Minum (Jakstrada SPAM) mengusahakan untuk mencapai sasaran RPJMN pada tahun 2019 akses air minum aman 100\%. [1]Berdasarkan RPJMN 2015-2019 dalam Perencanaan SPAM dilakukan strategi untuk mengutamakan pembangunan air minum yang memenuhi prinsip $4 \mathrm{~K}$ (kualitas, kuantitas, kontinuitas dan keterjangkauan) serta meningkatkan kesadaran masyarakat pada higienis dan sanitasi. [2]

Pemenuhan pelayanan air minum PDAM Kota Blitar menggunakan 7 sumur bor yang distribusikan untuk melayani di 3 wilayah pelayanan. Total jumlah penduduk 145.111 jiwa sekitar 38.160 jiwa aktif berlangganan PDAM. [3]Cakupan pelayanan PDAM sebesar 26\%, dengan keterangan 6.360 pelanggan yang aktif dari 11.940 sambungan terpasang. [4]

Cakupan pelayanan sebesar $26 \%$ untuk kota besar dinilai cukup rendah. Sedangkan pada RPJMD Kota Blitar menargetkan cakupan pelayanan mencapai $35 \%$ sambungan rumah pada tahun 2010-2015. Menurut RPJMD Kota Blitar akses air bersih keseluruhan (sambungan PDAM dan non sambungan) tahun 2015 sebesar 74,77 \% ditargetkan pada tahun 2019 telah mencapai 100\% akses air bersih. [5]

Berdasarkan hasil penelitian analisa kualitas pelayanan, PDAM Kota Blitar belum dapat memberikan kepuasan bagi pelanggannya. Dari kajian tersebut diharapkan bagi pihak PDAM Kota Blitar agar melakukan perbaikan terutama terkait dengan tingkat kejernihan air, bau dan rasa air karena kadar Fe dan Mn tinggi [6]. Oleh karena itu diperlukan studi lebih lanjut untuk peningkatan pelayanan air minum yang PDAM Kota Blitar.

\section{METODE PENELITIAN}

\section{A. Kerangka Perancangan}

Rangkaian kegiatan perancangan yang terdapat dalam kerangka perancangan dapat diuraikan sebagai berikut:

1) Ide studi

Ide penyusunan tugas akhir ini adalah melakukan perencanaan sistem distribusi PDAM Kota Blitar guna untuk memperbaiki dan meningkatkan pelayanan penyediaan air minum.

2) Studi literatur

Studi literatur merupakan tinjauan pustaka sebagai kegiatan memahami konsep perencanaan, mengumpulkan informasi terutama berkaitan dengan peraturan dan standar pemerintah dalam perencanaan sistem distribusi air minum.

3) Pengumpulan data

Data yang diperlukan dalam perencanaan pengembangan sistem distribusi Kota Blitar

a. Data Sekunder

Data sekunder yang di perlukan dalam kegiatan perancangan, antara lain:

- Peta Administrasi dan Peta RTRW Kota Blitar sebagai dasar penentuan wilayah pengembangan Kota Blitar.

- Data Eksisting PDAM Kota Blitar, antara lain persen pelayanan, jumlah pelanggan, dan lain lain. Digunakan sebagai data dasar perencanaan.

- Pipa eksisting PDAM Kota Blitar meliputi peta 
jaringan eksisting, lokasi sumur eksisting, dan Master Plan.

- Data kependudukan meliputi jumlah penduduk, penyebaran, serta kepadatan penduduk sebagai data yang digunakan untuk proyeksi pengembangan.

b. Data Primer

Data primer yang diperlukan dalam kegiatan perancangan, antara lain:

- Kondisi eksisting lokasi perancangan untuk mengetahui kondisi terbaru lokasi perancangan.

- Kondisi Pelayanan PDAM dilakukan dengan cara Real Demand Survey kepada pelanggan dan non pelanggan untuk mengetahui permasalah yang dialami masyarakat.

5) Pengolahan Data

Pengolahan data dilakukan menurut tata cara perencanaan SPAM dari Dinas PU. Pertama dilakukan adalah Keadaan eksisiting dengan data sekunder debit dan jaringan dari PDAM. Proyeksi penduduk dilakukan untuk memperkirakan jumlah penduduk yang akan dilayani pada masa yang akan datang. Selanjutnya kebutuhan air yang mempertimbangkan faktor kebutuhan air domestik, non domestik. Dan terakhir dilakukan perencanaan peningkatan pelayanan. [7] Sistem distribusi yang ditinjau adalah jaringan pipa yang tidak memenuhi kriteria yang belaku akan dilakukan evaluasi. [8]

\section{HASIL DAN PEMBAHASAN}

Pelayanannya PDAM Kota Blitar sudah mencakup 3 Kecamatan atau 21 Kelurahan. Air yang digunakan bersumber dari 7 sumur dalam yang dipompa dan didistribusikan ke pelanggan. Total sambungan rumah aktif bulan Oktober 2016 sebanyak 6360 unit dengan rata rata debit air yang terjual sebesar $77.602 \mathrm{~m}^{3} /$ bulan. Atau kebutuhan per orang sekitar 101,3 1/orang.hari sudah memenuhi untuk kategori kota sedang [9]

\section{A. Analisis Jaringan eksisting}

1) Analisis Debit Produksi

Sumber air produksi yang didistribusikan oleh PDAM Kota Blitar menggunakan 7 sumur bor dengan rata-rata debit pemompaan 7-15 1/s dan jam operasi 22 jam.

Tabel 1.

Data produksi air per Sumber Oktober 2016

\begin{tabular}{lcc}
\hline \multicolumn{1}{c}{ Nama Sumur } & Pemakaian (l/s) & Jam Operasi (Jam) \\
\hline S. B. V & 8 & 22 \\
S. D. X & 7 & 22 \\
S. B. XII & 8 & 23 \\
S. D. XVII & 15 & 23 \\
S. D. XVIII & 14 & 22 \\
S. D. XX & 15 & 12 \\
S. D. XIV & 1,2 & 22 \\
Jumlah & 57,2 & \\
\hline \hline
\end{tabular}

Didapatkan debit produksi total keseluruhan pompa sebesar 57,2 1/s. Debit produksi tersebut telah disesuaikan dengan data sekunder berupa monogram atau rekapitulasi laporan bulanan PDAM.
2) Analisa Kehilangan Air

Analisa kebutuhan air eksisting apabila dianalisa lebih lanjut dengan dibandingkan debit yang diproduksi akan diketahui tingkat kehilangan air pada sistem.

$$
\begin{aligned}
\% \text { kehilangan air } & =\frac{\text { Kehilangan air }}{\text { Debit Produksi }} \times 100 \% \\
& =\frac{27,4 \mathrm{l} / \mathrm{s}}{57,2 \mathrm{l} / \mathrm{s}} \times 100 \% \\
& =47 \%
\end{aligned}
$$

3) Penentuan Debit Tapping

Tujuan utama dari penentuan blok pelayanan ini adalah untuk mendapatkan debit yang mengalir pada setiap blok yang digunakan untuk simulasi aliran pada program Epanet. Penentuan debit dilakukan dengan cara membuat persentase blok yang melayani masing-masing kelurahan.

4) Analisis Jaringan Eksisting dengan Epanet

Adapun data-data yang perlu disiapkan adalah pertama adalah data base demand (debit blok), data panjang pipa, data elevasi tanah, jenis pipa yang digunakan, dan data lokasi pompa. Operasi sistem SPAM Kota Blitar dijelaskan pada diagram sistem Gambar 1 dengan keterangan pompa berwarna hijau yang aktif digunakan.

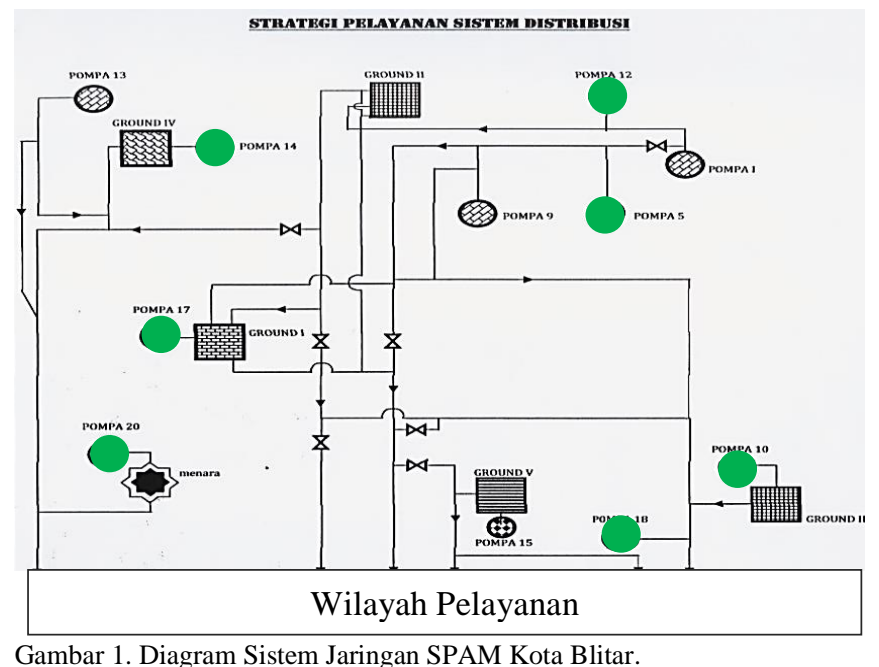

Pemompaan air pada sistem distribusi dilakukan tidak secara $24 \mathrm{jam}$ penuh. Oleh karena itu pada program Epanet digunakan pattern sesuai jadwal masing masing pompa. Contoh menu pattern yang digunakan untuk menginput jam operasi pada pompa $\mathrm{V}$ yang beroperasi 22 jam mulai 23.00 21.00 dapat dilihat pada Gambar 2.

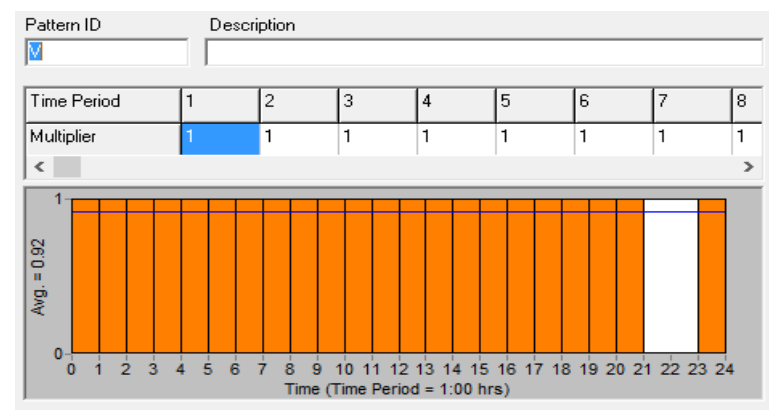

Gambar 2. Menu Pattern Editor untuk jam operasi pompa.

Upaya untuk mendapatkan debit produksi sesuai eksisting dengan mengasumsi kebocoran terdapat pada setiap tapping, 
sehingga debit tapping dapat dikalikan faktor Demand Multiplier untuk menambah kebocoran pada debit puncak.

$$
\begin{aligned}
\text { Faktor perbandingan } & =\frac{\text { Debit Produksi }}{\text { Debit Kebutuhan air }} \\
& =\frac{57,2 \% \mathrm{~s}}{29,8 \mathrm{l}}=1,91
\end{aligned}
$$

Untuk mengetahui kondisi jaringan eksisiting dianalisis pada running epanet Gambar 3.

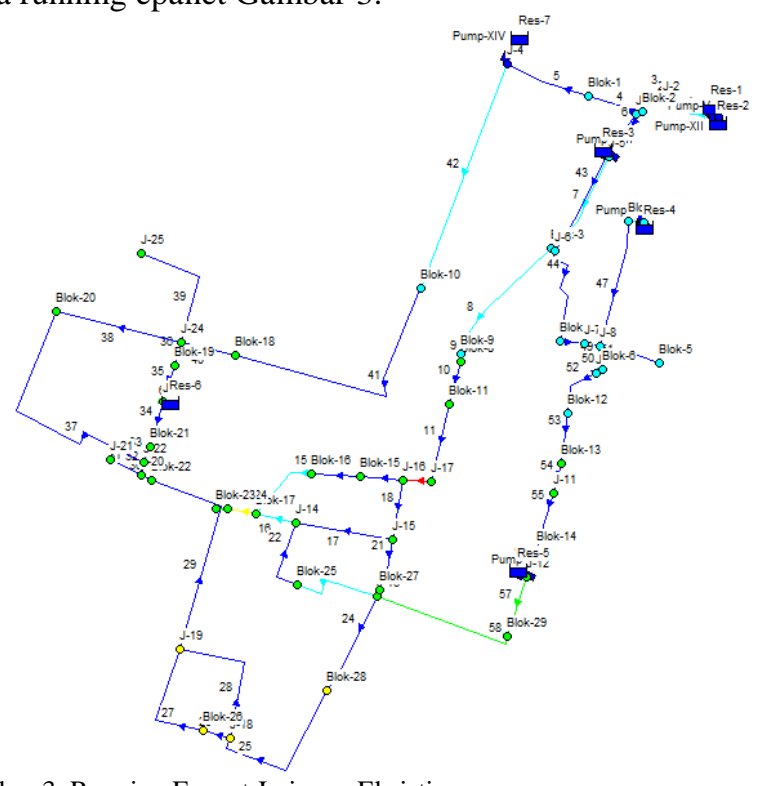

Gambar 3. Running Epanet Jaringan Eksisting

Dianalisis terdapat 40 pipa tidak memenuhi kriteria dengan kecepatan aliran kurang dari $0,3 \mathrm{~m} / \mathrm{s}$ (pipa berwarna biru tua) dan 2 buah pipa dengan kecepatan lebih dari $1,25 \mathrm{~m} / \mathrm{s}$ (pipa berwarna merah), Kecepatan yang kurang dari $0,3 \mathrm{~m} / \mathrm{s}$ berpotensi mengalami pengendapan lumpur, lumpur yang mengendap akan menyebabkan penyempitan diameter pipa.

Selain analisis kecepatan aliran pada pipa juga perlu analisis headloss karena berpengaruh pada tekanan pada junction. Pipa yang terlalu panjang serta dimeter pipa yang terlalu kecil akan meningkatkan headloss pada pipa sehingga dapat menurunkan tekanan. [10] Juntion blok dianalisis berdasarkan nilai pressure pada setiap junction blok minimal $10 \mathrm{~m}$ untuk memastikan air mencapai pelanggan, [11] dan maksimal $80 \mathrm{~m}$ untuk PVC tergantung pipa yang digunakan.

Terdapat 7 junction memiliki tekanan kurang dari $10 \mathrm{~m}$ (titik warna biru) dan sebagian besar terletak pada bagian utara. Contoh pada blok 1 memiliki tekanan $8,08 \mathrm{~m}$. Tekanan tersebut kurang dari kriteria yang disarankan (kriteria tekanan $10 \mathrm{~m}$ ), sehingga meningkatkan potensi air tidak mengalir ke pelanggan. Analisis dilakukan dengan melihat grafik time series tekanan Blok 1 dan 2 pada Gambar 4 dan Gambar 5.

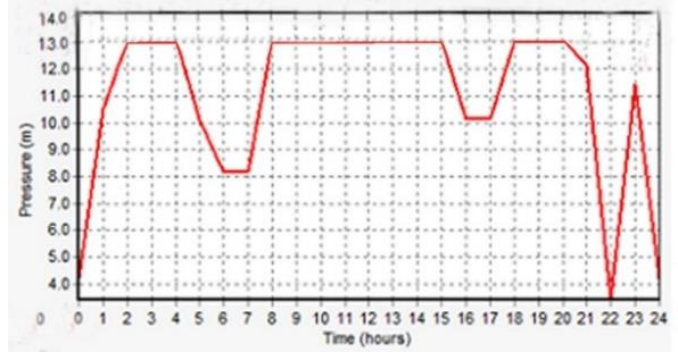

Gambar 4. Grafik Tekanan Time Series Blok 1

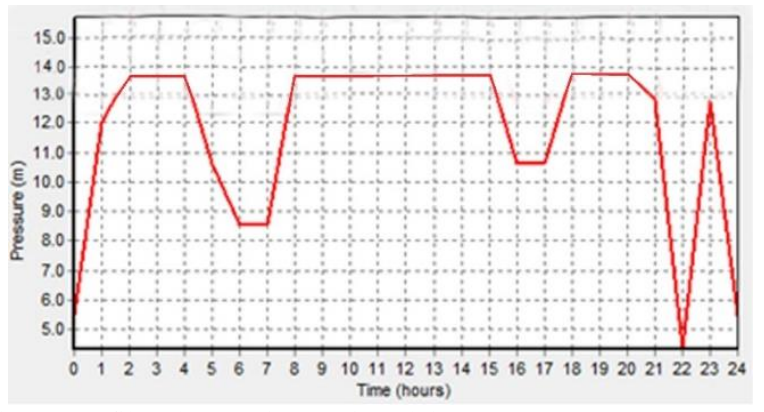

Gambar 5. Grafik Tekanan Time Series Blok 2

Grafik time series blok 1 dan blok 2 menunjukan bahwa aliran air pada blok tersebut tidak 24 jam. Untuk blok 1 ditunjukan dengan tekanan pada jam 6 sampai jam 7 semakin menurun dari $13,1 \mathrm{~m}$ menjadi 8,08 sedang blok 2 yang awalnya bertekanan 13,6 turun menjadi $8,74 \mathrm{~m}$. hal ini disebabkan oleh adanya jam puncak pada jam 06.00-07.00 dan jam 16.00-17.00 setelah jam puncak tekanan pada blok 1 dan 2 mulai meningkat menjadi normal kembali.

\section{B. Analisis Jaringan karena penyempitan diameter}

1) Kondisi jaringan primer

Analisis dilakukan hanya pada pipa dengan kecepatan yang kurang dari $0,3 \mathrm{~m} / \mathrm{s}$ karena berpotensi mengalami pengendapan suspended solid. Penyempitan diameter pipa diperkirakan $\pm 50 \%$ dari diameter sebelumnya, sehingga didapatkan diameter lebih kecil. Pada dasarnya kecepatan air merupakan faktor yang mempercepat pengendapan, sedangkan faktor utama yang meyebabkan pengendapan suspended solid adalah kualitas air. [12]Untuk mengetahui dampak yang terjadi pada sistem setelah terjadi penyempitan pada Gambar 6.

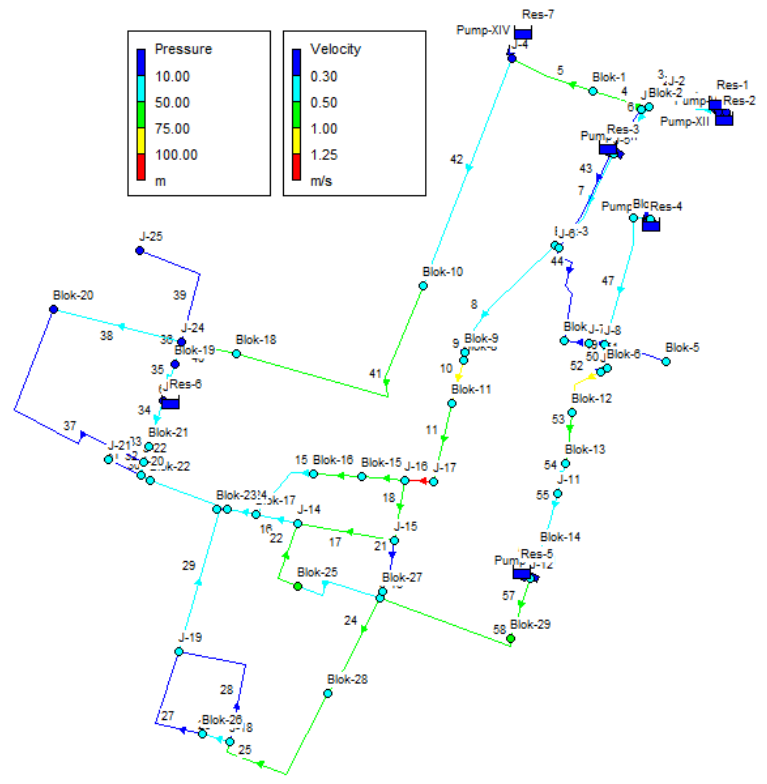

Gambar 6. Running Epanet Penyempitan Diameter

Running epanet didapatkan hasil dimana sebagian besar pipa mengalami percepatan aliran. Kecepatan air meningkan menandakan headloss pada pipa tersebut tinggi. Headloss yang besar dapat menurunkan tekanan pada junction selanjutnya, seperti yang terjadi pada junction blok no 19 sampai 21. Karena headloss pipa 40 mencapai $11,28 \mathrm{~m} / \mathrm{km}$ dan pipa 36 memiliki headloss 2,41 
$\mathrm{m} / \mathrm{km}$, sehingga pada juntion blok 19 yang awalnya memiliki tekanan $\pm 50 \mathrm{~m}$ setelah penyempitan diameter hanya memiliki tekanan $2,5 \mathrm{~m}$.

\section{2) Kondisi mikro sistem memiliki tekanan kritis}

Dari analisis jaringan primer didapatkan 4 node blok yang meiliki tekanan kurang dari $10 \mathrm{~m}$, yaitu node blok 1 $(5,04 \mathrm{~m})$, blok $2(6,06 \mathrm{~m})$, blok $19(2,5 \mathrm{~m})$, dan blok 20 $(2,03 \mathrm{~m})$. Analisis detail mikro sistem setiap blok pada Gambar 7 - Gambar 10.

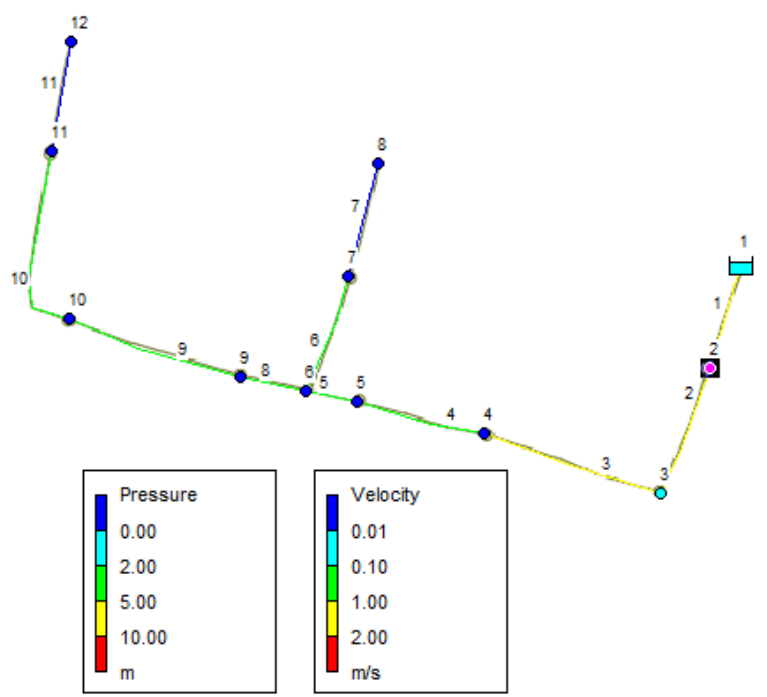

Gambar 7. Detail Mikro Sistem Blok 1

- Beberapa junction memiliki tekanan bernilai negatif

- Debit yang dialirkan lebih besar dibandingkan dengan diameter pipa yang terpasang 2 "

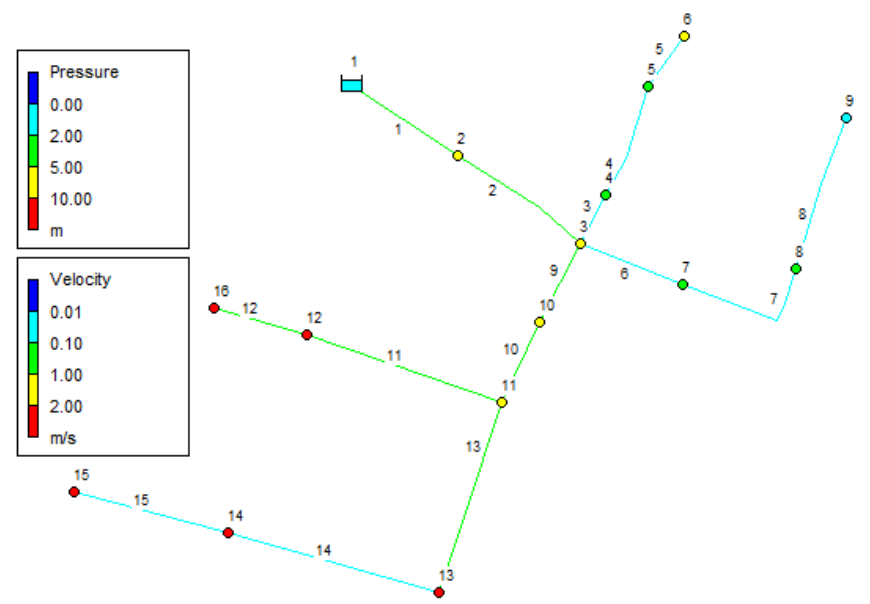

Gambar 8. Detail Mikro Sistem Blok 2

- Seluruh junction masih memiliki tekanan bernilai positif

- Rata-rata memiliki sisa tekan 2,55 - 15,3 m (air masih mengalir)

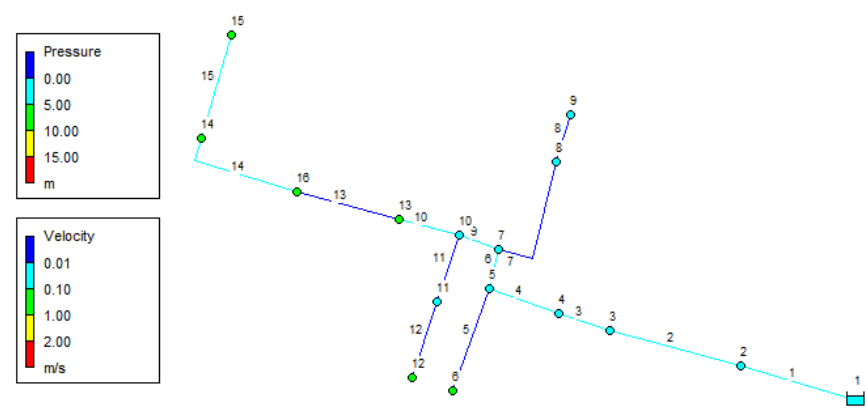

Gambar 9. Detail Mikro Sistem Blok 19

- Seluruh junction masih memiliki tekanan bernilai positif

- Rata-rata memiliki sisa tekan 2,5-5,5 m (air masih mengalir)

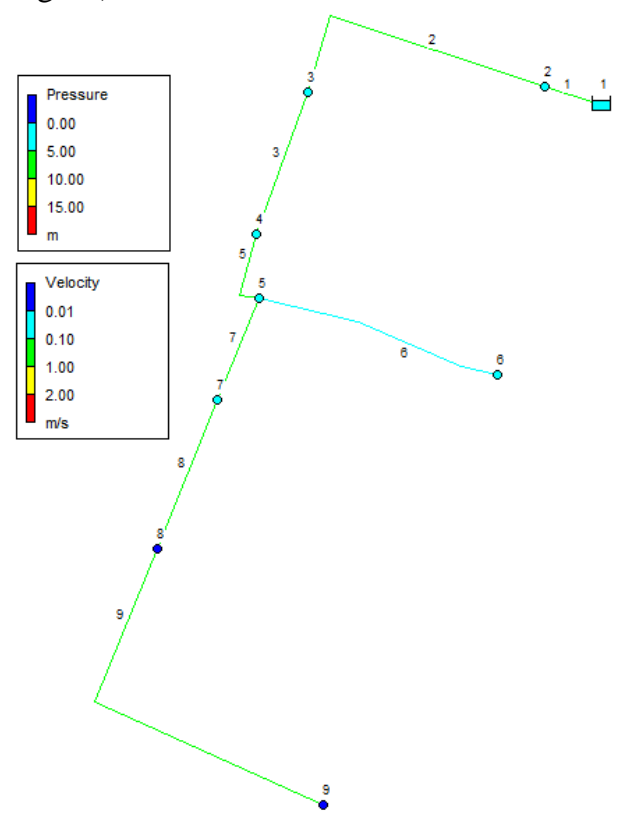

Gambar 10. Detail Mikro Sistem Blok 20

- 2 junction terjauh memiliki tekanan negatif

- Permasalahan tersebut terjadi karena pipa sekunder cukup panjang

\section{Perencanaan Pengembangan Pelayanan}

1) Proyeksi Penduduk

Perhitungan proyeksi penduduk dilakukan dengan menghitung nilai koefisien korelasi 3 metode, yaitu metode aritmatik, geometrik, dan least square. Koefisien kolerasi yang relevan ditandai dengan hasil koefisien yang mendekati 1 sehingga apabila diplot pada grafik pertumbuhan penduduk akan linier. [13]

Didapatkan nilai koefisien korelasi metode geometrik sebesar 0,618 yang mendekati 1. Perhitungan proyeksi dilakukan perkelurahan dengan menentukan nilai koefisien korelasi masing masing kelurahan. Berikut contoh perhitungan proyeksi penduduk tahun 2016 kelurahan sukorejo $(r=0,0371)$

- Penduduk Kelurahan Sukorejo

$$
\begin{array}{ll}
\mathrm{Po}_{(2015)} & =14091 \text { jiwa } \\
\mathrm{dn} & =2016-2015=1 \\
\mathrm{r} & =0,0371
\end{array}
$$


Maka proyeksi penduduk kelurahan sukorejo tahun 2016,

$P n=P o \times(1+r)^{d n}$

$P n=14091 \times(1+0,0371)^{1}=14614$ jiwa

Proyeksi penduduk Kota Blitar pada tahun 2021 sebanyak 160886 jiwa dan pada tahun 2026 sebanyak 174809 jiwa.

2) Perhitungan Kebutuhan Air

a) Kebutuhan Domestik

Jumlah penduduk th $2021=3049$ jiwa

Pemakaian per orang $\quad=100 \mathrm{Lt} /$ Orang/Hari

Debit

$=\frac{\text { Jumlah penduduk terlayani } \times \text { Konsumsi per orang }}{86400}$

$=\frac{3049 \text { jiwa } \times 100 \mathrm{Lt} / \text { orang. hari }}{86400}=3,53 \mathrm{l} / \mathrm{s}$

- Kebutuhan Non Domestik

Fasilitas Sekolah $\quad=0,591 / \mathrm{s}$

Fasilitas Puskemas $\quad=0,0121 / \mathrm{s}$

Fasilitas Rumah Sakit $\quad=01 / \mathrm{s}$

Fasilitas Hotel $\quad=0,013 \mathrm{l} / \mathrm{s}$

Fasilitas Tempat Ibadah $=0,221 / \mathrm{s}$

Fasilitas Industri $\quad=4,25 \mathrm{l} / \mathrm{s}$

Fasilitas Industri $\quad=0,28 \mathrm{l} / \mathrm{s}$

Fasilitas Industri $\quad=1,46 \mathrm{l} / \mathrm{s}$

$$
\begin{aligned}
\text { - Debit Total } & =\Sigma \text { Domestik }+\Sigma \text { Non Domestik } \\
& =3,58+7,04 \\
& =10,63 \mathrm{l} / \mathrm{s}
\end{aligned}
$$

Dilakukan perhitungan untuk setiap kelurahan dengan cara yang sama. Tahap 1 pada tahun 2017-2021 dan tahap 2 pada tahun 2022-2026. Didapatkan debit pengembangan Kota Blitar pada tahap 1 sebesar 131 1/s dan pada tahap 2 sebesar $151 \mathrm{l} / \mathrm{s}$.

3) Analisis Sistem Pengembangan Tahap 1

Pengembangan tahap 1 pada tahun 2017-2021 dengan debit 131 1/s. Analisis tahap 1 dapat dilihat pada Gambar 11.

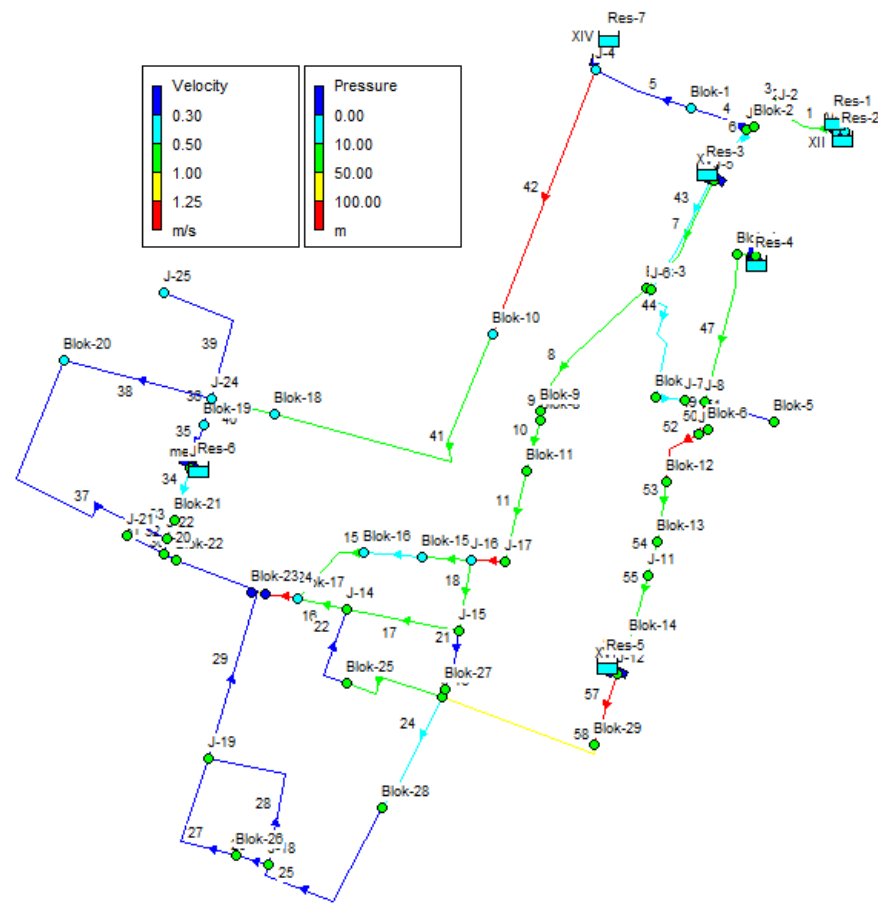

Gambar 11. Running Sistem Pengembangan Tahap 1.

Running epanet pengembangan tahap 1 didapatkan sistem masih dapat menampung pertambahan debit sebesar $131 \mathrm{l} / \mathrm{s}$. Hanya saja perlu adanya evaluasi dan perbaikan dibeberapa pipa, seperti pada pipa nomor 12, 15, 19, 20, 42, 48, 49, 52, 57 dan 58 yang memiliki headloss yang sangat tinggi (garis berwarna merah). Headloss yang tinggi akan mengurangi tekanan pada junction, seperti yang terjadi pada junction blok $10,15,16,17,18,19,23$ dan 24 memiliki tekanan kurang dari $10 \mathrm{~m}$ bahkan negatif (titik berwarna biru).

Headloss yang tinggi tersebut diperkirakan karena diameter yang terpasang lebih kecil dibandingkan debit yang masuk. Penanganannya memasang pipa paralel pada pipa dengan headloss yang tinggi untuk meningkatkan luas penampang sehingga dapat menurunkan headloss. [14]Hasil running epanet dengan perbaikan pipa paralel pada Gambar 12. 


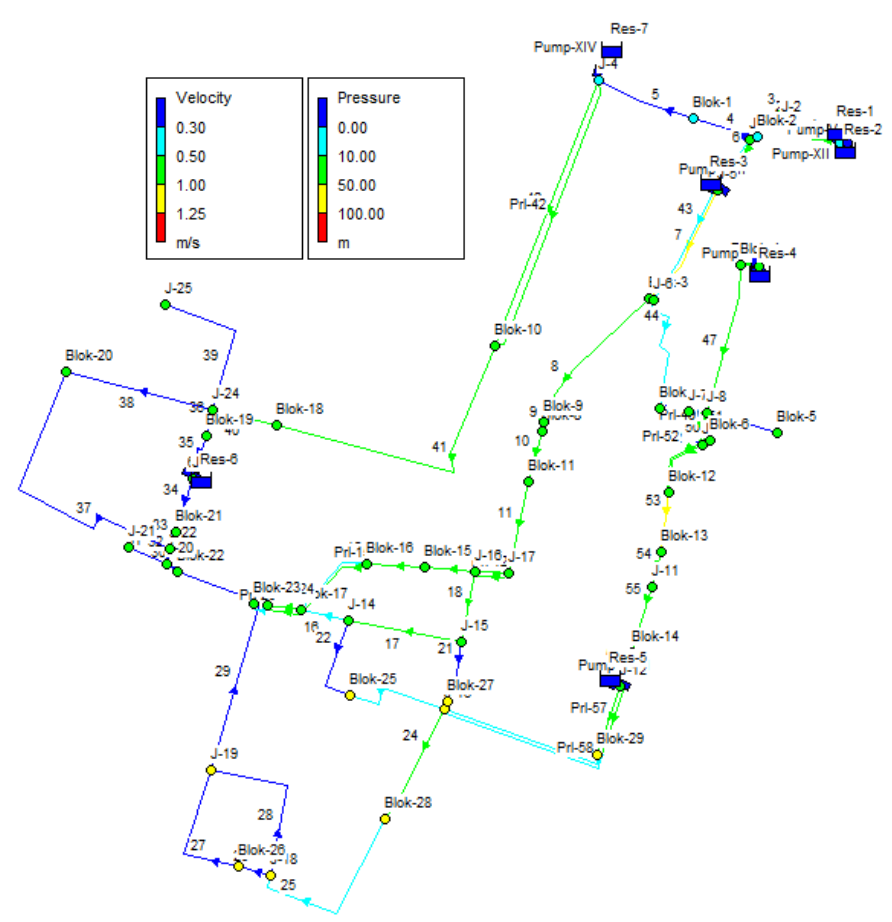

Gambar 12. Running Sistem Perbaikan dengan Pipa Paralel.

Setelah memasang 10 buah pipa paralel dengan ukuran pipa 6' dan 8' menyebabkan headloss pipa nomor 12,15 , 19, 20, 42, 48, 49, 52, 57 dan 58 sudah menurun. Contoh pada pipa nomor 19 yang awalnya memiliki headloss $52,06 \mathrm{~m}$ setelah dipasang pipa paralel headloss turun menjadi 4,18 m. Untuk tekanan junction blok 10, 15, 16, 17, 18, 19, 23 dan 24 mulai meningkat. Contoh blok 10 sebelumnya bertekanan $5,71 \mathrm{~m}$ naik menjadi $31,84 \mathrm{~m}$.

4) Analisis Sistem Pengembangan Tahap 2

Pengembangan tahap 2 pada tahun 2022-2026 dengan debit 131 1/s. Analisis tahap 1 dapat dilihat pada Gambar 13.

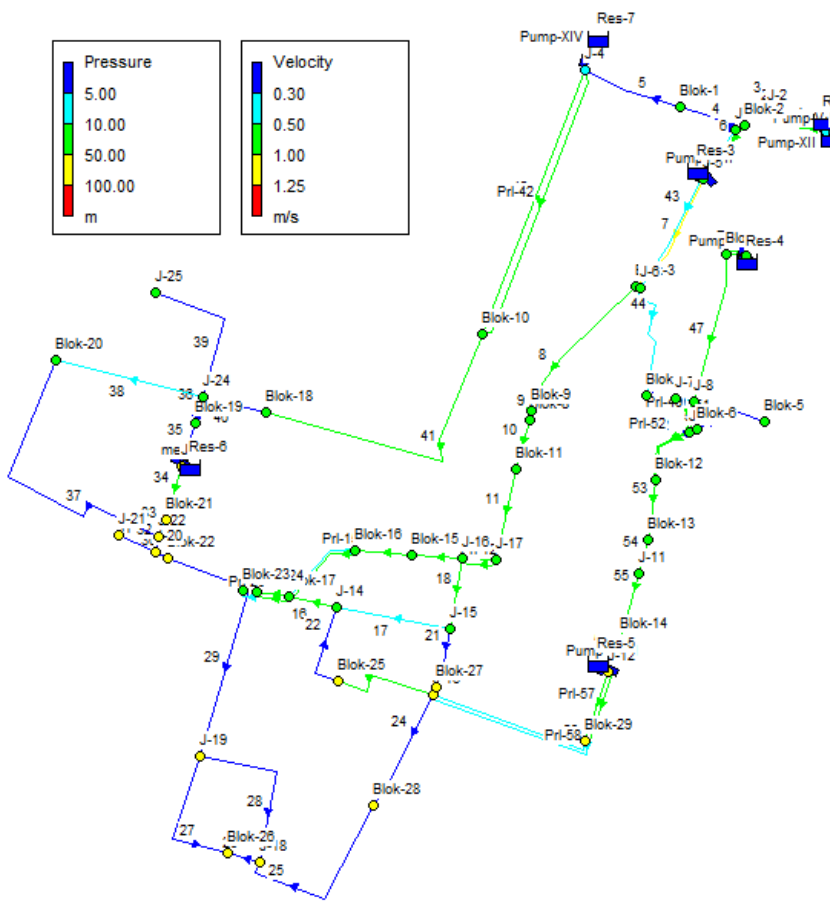

Hasil running epanet dapat diketahui dari gambar kecepatan aliran pada pipa telah memenuhi kriteria pada range $0,3-1$ $\mathrm{m} / \mathrm{s}$ serta headloss pipa tidak melebihi $20 \mathrm{~m}$. Untuk analisis junction sendiri tidak ada yang bernilai negatif (tidak berwarna biru) sehingga air dapat mengalir pada setiap titik junction. Dari analisis tersebut dapat disimpulkan bahwa sistem masih dapat menampung peningkatan debit tahap 2 tanpa perlu adanya penanganan khusus.

\section{KESIMPULAN}

Berdasarkan penelitian yang telah dilakukan, maka dapat diambil kesimpulan sebagai berikut:

1) Berdasarkan survey pelanggan yang dilakukan terdapat endapan $\mathrm{Fe}$ yang menyebabkan air pelanggan keruh (kecoklatan) dan bau besi.

2) Terdapat 41 pipa memiliki kendala kecepatan aliran air tidak memenuhi kriteria $(<0,3 \mathrm{~m} / \mathrm{s})$ akan memberikan kesempatan suspended solid $\left(\mathrm{Fe}(\mathrm{OH})_{3}\right)$ untuk mengendap.

3) Untuk mengatasi endapan suspended solid dapat menggunakan beberapa cara seperti wash out, air scoring, swabbing, dan memasang pipa parallel.

4) Pemasangan pipa paralel dapat menurunkan headloss pipa dan meningkatkan tekanan pada junction.

5) Peningkatan pelayanan 10 tahun kedepan membutuhkan debit sebesar 151,27 1/d. serta kapasitas sumber air dan jaringan masih dapat menampung peningkatan tersebut.

\section{DAFTAR PUSTAKA}

[1] D. P. D. J. C. Karya, Standar Pelayanan Minimal Bidang Pekerjaan Umum dan Penataan Ruang,. Jakarta, 2010.

[2] P. P. D. Consultan, Rencana Pengamanan Air Minum (RPAM). Jakarta: Satuan Kerja Direktorat Pengembangan Air Minum Direktorat Jendral Cipta Karya Kementrian Pekerjaan Umum, 2012.

[3] BSN Kota Blitar, Kota Blitar dalam angka tahun 2016. Blitar, 2016.

[4] P. K. Blitar, Rencana Induk Sistem Penyediaan Air Minum (RISPAM). 2016.

[5] P. K. Blitar, Kebijakan dan Strategi Daerah Pengembangan Sistem Penyediaan Air Minum (Jakstrada PSPAM) Kota Blitar. 2016.

W. Handojo, "Analisa Kualitas Pelayanan Perusahaan Daerah Air Minum Kota Blitar," Institut Teknologi Sepuluh Nopember., 2007.

D. P. D. J. C. Karya, Buku Panduan Pengembangan Air Minum. Jakarta, 2007.

[8] D. Kimpraswil, Pedoman/Petunjuk Teknik dan Manual KIMPRASWIL. Badan Penelitian dan Pengembangan, 2002.

[9] B. S. Nasional, SNI 19-6728.1-2002 Penyusunan Neraca Sumber Daya. Jakarta, 2002.

[10] S. dan M. T. Noerbambang, Perancangan dan Pemeliharaan Sistem Plambing. Jakarta: Pradnya Paramita, 2000.

[11] D. P. D. J. C. Karya, Permen PU Tentang Penyelenggaraan Pengembangan SPAM. Jakarta, 2007.

[12] N. Said, Metode Praktis Penghilangan Zat Besi dan Mangan didalam Air Minum,. Jakarta: Badan Pengkajian dan Penerapan Teknologi, 2007.

[13] A. Supangat, Statistika: Dalam Kajian Deskriptif Inferensi dan Nonparametrik. Jakarta: Kencana Prenada Media Group, 2010.

[14] A. Safii, "Evaluasi Jaringan Sistem Penyediaan Air Bersih di PDAM Kota Lubuk Pakam," Universitas Sumatera Utara, 2012. 